\title{
Editorial: Estimulação Transcraniana de Corrente Contínua, em Parkinson - Revisão Sistemática
}

\author{
Fernando Rodrigues de Carvalho \\ Cirurgião dentista, Doutor, Neuro-Sono, UNIFESP, São Paulo-SP, Brasil.
}

Desde 1665, quando apareceram as revistas científicas na França e na Inglaterra, estas se firmaram como principal meio de comunicação entre os cientistas e tornaram-se cada vez mais importantes com a evolução da ciência, da terapêutica e com a necessidade do embasamento científico ${ }^{1}$.

O embasamento científico tornou-se essencial para a tomada de decisão clínica em saúde, a partir do final dos anos 40, quando houve um crescente na produção e publicação dos estudos clínicos, no entanto, muitos estudos clínicos que são publicados não têm a qualidade necessária para se tornar uma fonte confiável de tomada de decisão em saúde, portanto devem ser avaliados antes de guiarem os profissionais de saúde na tomada de decisão do melhor tratamento a ser oferecido a seu paciente ${ }^{2}$.

Em 1992 surge a medicina baseada em evidências (MBE), com o objetivo de promover a relação entre as melhores evidências científicas obtidas através das pesquisas clínicas com a habilidade clínica e a escolha do paciente ${ }^{3}$.

A revisão sistemática tem como finalidade responder a uma pergunta claramente formulada sobre a "efetividade" de uma intervenção, pois caracteriza-se por ser um estudo secundário, que utiliza métodos sistemáticos, explícitos e pré definidos com busca ampla e independente de idioma para identificar, selecionar e avaliar criticamente estudos primários relevantes e coletar dados de estudos incluídos na revisão. Também reúne de forma organizada muitos resultados de pesquisas clínicas e auxilia na explicação de diferenças encontradas entre estudos primários que investigam a mesma questão, facilitando a elaboração de diretrizes clínicas, sendo extremamente útil para "tomadores" de decisão na área de saúde ${ }^{4-6}$.

O ensaio clínico é o melhor estudo de pesquisa clínica, mas está sempre sendo ameaçado por vários tipos de vieses que se iniciam desde a idealização da pesquisa até a sua publicaçáo. Quanto menor a quantidade de vieses for incorporada em uma pesquisa, melhor será sua qualidade e mais aceita ela será. A qualidade de um estudo está relacionada com a validade interna e dependerá de como a pesquisa clínica foi delineada, conduzida e analisada. A validade interna de uma pesquisa não é suficiente para ela ser de utilidade, no entanto, é uma condição necessária ${ }^{7}$.

A revisão sistemática realizada por Vega e Costa, "Estimulación Transcraneal de Corriente Directa en Parkinson" publicada neste volume da Revista Neurociências, utilizou o método Jadad ${ }^{9}$ para verificação da validade interna e consequentemente da qualidade dos estudos clínicos primários, o que traz uma maior confiabilidade aos resultados apresentados.

Apesar desta revisão sistemática não apresentar muitos estudos incluídos, os que foram incluídos tiveram uma boa qualidade o que nos faz considerar que a estimulação transcraniana por corrente contínua pode constituir uma importante opção terapêutica para a doença de Parkinson principalmente por ser um método não invasivo, seguro, não interfere nas terapias tradicionais e que não causa dor, resultando em melhora nas habilidades motoras e cognitivas. Além disso, esta revisão sistemática cumpre outra função importantíssima que é o de mapear o conhecimento e orientar a execuçáo de futuros ensaios clínicos controlados randomizados, os quais devem ser realizados com grande rigor metodológico privilegiando questôes importantes como: o número de sessóes, a intensidade, a duração do tempo de estimulação, a permanência da excitabilidade cortical após a estimulaçẫo e a posição exata dos eletrodos no córtex cerebral, para a utilização ampla desta terapêutica, que se mostra promissora.

A existência de uma revisão sistemática é muito útil tanto para para o clínico, profissional da saúde, que interessado em saber se um tratamento é melhor que outro, quanto para o pesquisador interessado em conduzir 
uma pesquisa no assunto. Ambos devem sempre iniciar sua pesquisa na literatura por uma revisão sistemática, pois o clínico poderá obter a resposta sobre qual o melhor tratamento disponível e, de acordo com sua experiência clínica, nas circunstâncias de atendimento, situação local e as particularidades e desejos dos doentes poderá tomar uma melhor decisão clínica. Já para o pesquisador, a revisão sistemática, trará informações importantes sobre os estudos clínicos existentes permitindo que se conheça suas limitaçôes antes de se iniciar um novo estudo clínico, evitando possíveis vieses que comprometerão a validade interna do estudo e também se obtém a necessidade de se responder a perguntas ainda sem respostas, como ocorre nesta revisão ${ }^{10}$.

A doença de Parkinson tem importante relevância clínica, pois é uma doença muito prevalente e merece que todos os esforços sejam feitos para promover a melhora da qualidade de vida de seus portadores, devendo-se considerar que a incidência desta doença tende a aumentar com o envelhecimento da população.

\section{REFERÊNCIAS}

1.Pereira MG. Para que servem os periódicos científicos. Brasília Méd 2001;38(1/4):3-4.

2.Silva Filho CR, Saconato H, Coterno LO, Marques I, Atallah AN. Avaliação da qualidade de estudos clínicos e seu impacto nas metanálises. Rev Saúde Pública 2005;39(6):865-873.

http://dx.doi.org/10.1590/S0034-89102005000600001

3.Sackett DL, Straus SE, Richardson WS, Rosenberg W, Haynes RB. Medicina baseada em evidências: prática e ensino. 2. ed. Porto Alegre: Artmed, 2003.

4.Atallah AN. Revisão sistemática e metanálise. In: Atallah AN,Castro AA, editores. Medicina baseada em evidências: fundamentos da pesquisa clínica. São Paulo: Lemos-Editorial 1998:42-48.

5.Centro Cochrane do Brasil. Laboratório de Ensino a Distância da UNIFESP/EPM. Curso de revisão sistemática e metanálise [curso a distância]. São Paulo: Centro Cochrane do Brasil; 2004. [citado 2006 Abr 19]. Disponível em: http://www.virtual.epm.br/cursos/metanalise/

6.Alderson P, Green S, editors. Cochrane Collaboration open learning material for reviewers 1.1. In: The Cochrane Collaboration. November 2002.

7.Fletcher RH; Fletcher SW; Wagner EH. Epidemiologia Clínica: elementos essenciais. 3. ed. Porto Alegre: Artmed, 1996.

8.Vega DMP, Costa MLG. Estimulación Transcraneal de Corriente Directa en Parkinson - Revisión Sistemática. Rev Neurocienc 2013;21(3):356-63.

http://dx.doi.org/10.4181/RNC.2013.21.841.8p

9.Jadad AR. Randomised controlled trials: a user's guide. Disponível em: www. cgmh.org.tw/intr/intr5/c6700/obgyn/f/randomized\%20tial/index.html 10.Carvalho FR, Lentini-Oliveira DA, Machado MAC, Carvalho JEC, Barros MR, Prado LBF, Carvalho LBC, Prado GF. Comentário Crítico Sobre Revisão Sistemática Baseado no Artigo: Benzodiazepínicos e Drogas Relacionadas para Insônia no Cuidado Paliativo. Rev Neurocienc 2012;20(1):13-25.

http://dx.doi.org/10.4181/RNC.2011.IP.13 